\title{
A Robust Static Headspace GC-FID Method to Detect and Quantify Formaldehyde Impurity in Pharmaceutical Excipients
}

\author{
Bashir Daoud Agha Dit Daoudy (D, ${ }^{1}$ Mohammad Ammar Al-Khayat, ${ }^{1}$ \\ Francois Karabet, ${ }^{2}$ and Mohammad Amer Al-Mardini ${ }^{1}$ \\ ${ }^{1}$ Department of Pharmaceutical Chemistry and Quality Control, Faculty of Pharmacy, Damascus University, Damascus, Syria \\ ${ }^{2}$ Department of Chemistry, Faculty of Science, Damascus University, Damascus, Syria \\ Correspondence should be addressed to Bashir Daoud Agha Dit Daoudy; bashir-daoudy@hotmail.com
}

Received 20 June 2017; Accepted 17 October 2017; Published 4 March 2018

Academic Editor: Krishna K. Verma

Copyright ( 2018 Bashir Daoud Agha Dit Daoudy et al. This is an open access article distributed under the Creative Commons Attribution License, which permits unrestricted use, distribution, and reproduction in any medium, provided the original work is properly cited.

\begin{abstract}
Formaldehyde is a highly reactive impurity that can be found in many pharmaceutical excipients. Trace levels of this impurity may affect drug product stability, safety, efficacy, and performance. A static headspace gas chromatographic method was developed and validated to determine formaldehyde in pharmaceutical excipients after an effective derivatization procedure using acidified ethanol. Diethoxymethane, the derivative of formaldehyde, was then directly analyzed by GC-FID. Despite the simplicity of the developed method, however, it is characterized by its specificity, accuracy, and precision. The limits of detection and quantification of formaldehyde in the samples were of 2.44 and $8.12 \mu \mathrm{g} / \mathrm{g}$, respectively. This method is characterized by using simple and economic GC-FID technique instead of MS detection, and it is successfully used to analyze formaldehyde in commonly used pharmaceutical excipients.
\end{abstract}

\section{Introduction}

Although considered pharmacologically nonactive, pharmaceutical excipients have critical effects on drug product safety, efficacy, and quality. During early stages of drug formulation development, excipients are evaluated for appropriateness by studying their physical and chemical compatibility with drug substances under stressed and accelerated conditions. Depending on the results of the compatibility studies, formulator can exclude incompatible excipients from later stages of formulation development. Chemical incompatibility with drug substances may result not only from direct reaction with excipients but also from reaction with excipient impurities. These impurities include formaldehyde which could be generated by autoxidation degradation of many pharmaceutical excipients such as polyvinylpyrrolidone (PVP) and polyethylene glycol (PEG) [1-4].

Pharmacopoeial monographs of pharmaceutical excipients rarely require testing for formaldehyde specifically $[5,6]$. However, formaldehyde may negatively affect safety, efficacy, chemical stability, and performance of dosage forms, even in trace amounts. It can form adducts with many pharmaceuticals containing nucleophilic functional groups, especially amine and hydroxyl groups $[1,2,4]$, such as gelatin [7], varenicline [8], irbesartan [9], phenylephrine [10], and GDC-0973 [11]. Some of these adducts may have toxic effects such as the degradation product of melatonine with formaldehyde [12].

Formaldehyde has a low molecular weight and a high chemical reactivity. Furthermore, it has little UV activity and low detector sensitivity and specificity. Besides, it is soluble in both water and organic solvents. As a consequence, it is difficult to directly extract and determine formaldehyde in a specific, accurate, and sensitive way. Therefore, most of the analytical methods used for formaldehyde analysis employ chemical derivatization to improve its stability and modify the physicochemical properties to enhance its detectability [11, 13-17].

Many analytical methods have been developed to determine formaldehyde in pharmaceuticals and cosmetics. These methods are based on colorimetric, spectrophotometric, 
fluorescent, capillary electrophoresis, HPLC, GC, and GC-MS techniques [1, 17-20]. Lots of the reported methods have relied on derivatizing formaldehyde using acetylacetone or chromotropic acid reagents prior to colorimetric and/or spectrophotometric determination. However, the main disadvantages of these methods are the lack of appropriate specificity and/or sensitivity $[1,17,20,21]$. 2,4-Dinitrophenylhydrazine, the most popular derivatization reagent, has been used before determination of formaldehyde by HPLC [11, 15, 22]. However, some of these methods have limited selectivity or have suffered from difficulty handling and injecting excipient samples which form viscous solution (such as PVP). In addition, other HPLC methods require tedious and multisteps extraction procedures and/or long analysis time $[1,16,20,23]$. Gas chromatography is the best choice for determination of volatile components, especially when associated with the headspace sampling technique. This technique provides a simple way to directly inject the extracted volatiles into GC. In contrast with the direct injection of the sample solution into GC inlet, the headspace injection allows the volatiles to be analyzed without interference by the nonvolatile matrix. By using the headspace technique, analysts can also simply derivatize target components by utilizing the headspace vial as a reaction vessel [24]. Few GC methods have been developed to determine formaldehyde in pharmaceutical excipients; however, the derivatization reaction, the extraction, and/or the sample preparation were generally complex and/or required long time $[13,16,19,20]$. del Barrio et al. reported a headspace GC-MS method for determination of formaldehyde in some excipients by converting it to diethoxymethane using acidified ethanol. In this method, the sample preparation was very simple and rapid, and the chemical derivatization can be carried out under mild conditions. However, the authors did not evaluate the capability of using FID for quantification [16]. Although FID is less sensitive than MSD, it is the most widely used detector for routine quantification in typical analytical laboratories. In addition, it is easier to operate and maintain [20,25].

As most of the spectrophotometric methods have some disadvantages, while other chromatographic methods are complex to be performed, the aim of this research is to develop and validate a static headspace (SHS) GC-FID method to determine formaldehyde, and then to use it as a screening method and a quality control tool to analyze this impurity in commonly used pharmaceutical excipients.

\section{Materials and Methods}

2.1. Standards, Reagents, and Chemicals. High-purity diethoxymethane $(\geq 99.0 \%)$ was purchased from Aldrich (USA). Absolute ethanol (99.9\%) and pure formic acid were purchased from Panreac (Spain). Formaldehyde solution (37-41\%) was obtained from SCP (England). ACS grade $p$-toluenesulfonic acid monohydrate $(\geq 98.5 \%)$ was purchased from Sigma-Aldrich (Japan). All excipients used were of pharmaceutical grade.

2.2. Instrumentation. Experiments were conducted by Agilent Model 7890A gas chromatograph equipped with mass selective detector (MSD model 5975C) and associated with GC sampler 80 enhanced with Agilent PAL headspace option. Agilent MSD Productivity ChemStation E.02.01.1177 software was used to control, acquire, and process the chromatographic data. A $30 \mathrm{~m} \times 0.25 \mathrm{~mm}$ i.d. ZB-WAX column with $0.25 \mu \mathrm{m}$ film thickness (Phenomenex, USA) was utilized for gas chromatographic separation.

2.3. Headspace Sampling Parameters. The headspace autosampler parameters were set as follows: incubation temperature: $70^{\circ} \mathrm{C}$; incubation time: $25 \mathrm{~min}$ for PVP samples and 15 min for PEG samples; syringe temperature: $75^{\circ} \mathrm{C}$; agitation speed: $500 \mathrm{rpm}$; syringe injection volume: $800 \mu \mathrm{l}$; syringe fill speed: $100 \mu \mathrm{l} / \mathrm{s}$; syringe injection speed: $1000 \mu \mathrm{l} / \mathrm{s}$; fill strokes: 1; pull-up delay: $2 \mathrm{~s}$; pre- and postinjection delay: 0.2 and $0.4 \mathrm{~s}$, respectively. Carryover in the headspace syringe was eliminated by an automatic syringe flush performed after each injection.

2.4. GC Instrumental Conditions. The injector was maintained at $170^{\circ} \mathrm{C}$ with a split ratio of $1: 25$. The column oven temperature program involved an initial temperature of $35^{\circ} \mathrm{C}$ for $5 \mathrm{~min}$ and increased at $40^{\circ} \mathrm{C} / \mathrm{min}$ to $220^{\circ} \mathrm{C}$ and held for $1 \mathrm{~min}$. The carrier gas was helium (99.999\%) at a constant flow rate of $0.9 \mathrm{~mL} / \mathrm{min}$. FID was set at $280^{\circ} \mathrm{C}$ for quantification. MS detection was carried out at $230^{\circ} \mathrm{C}$ with full scan (31-250 amu) for identification.

2.5. Sample Preparation. Samples were prepared by directly weighing $250 \mathrm{mg}$ of the tested excipient into a $20 \mathrm{ml}$ amber headspace vial (Supelco). After that, $5 \mathrm{~mL}$ of the solution of $1 \%$ (w/w) $p$-toluenesulfonic acid in ethanol was added to the content of each sample vial which was then immediately sealed with a magnetic screw cap lined with a butyl/polytetrafluoroethylene septum (Supelco) and shaken for 2 minutes (until the content becomes completely dissolved). Finally, the prepared vials were sequenced and automatically moved to the incubator for completing the chemical derivatization of formaldehyde.

2.6. Standards Preparation. The concentration of formaldehyde solution was determined by applying the iodometric method described in British Pharmacopoeia 2013 [5]. The concentration was $35.10 \%(\mathrm{w} / \mathrm{w})$.

Standard solutions of formaldehyde were prepared in the acidified ethanol (1\% p-toluenesulfonic acid). A stock standard solution of formaldehyde at $1251.063 \mu \mathrm{g} / \mathrm{ml}$ was prepared and used to prepare a series of standard solutions at lower concentrations by serial dilutions. Then, $5 \mathrm{~mL}$ of each standard solution was transferred to a headspace vial and treated as described above.

2.7. Method Validation. The method was validated in terms of specify, linearity, accuracy, repeatability, intermediate precision, limit of detection, and limit of quantification according to British Pharmacopoeia 2013 [5]. 

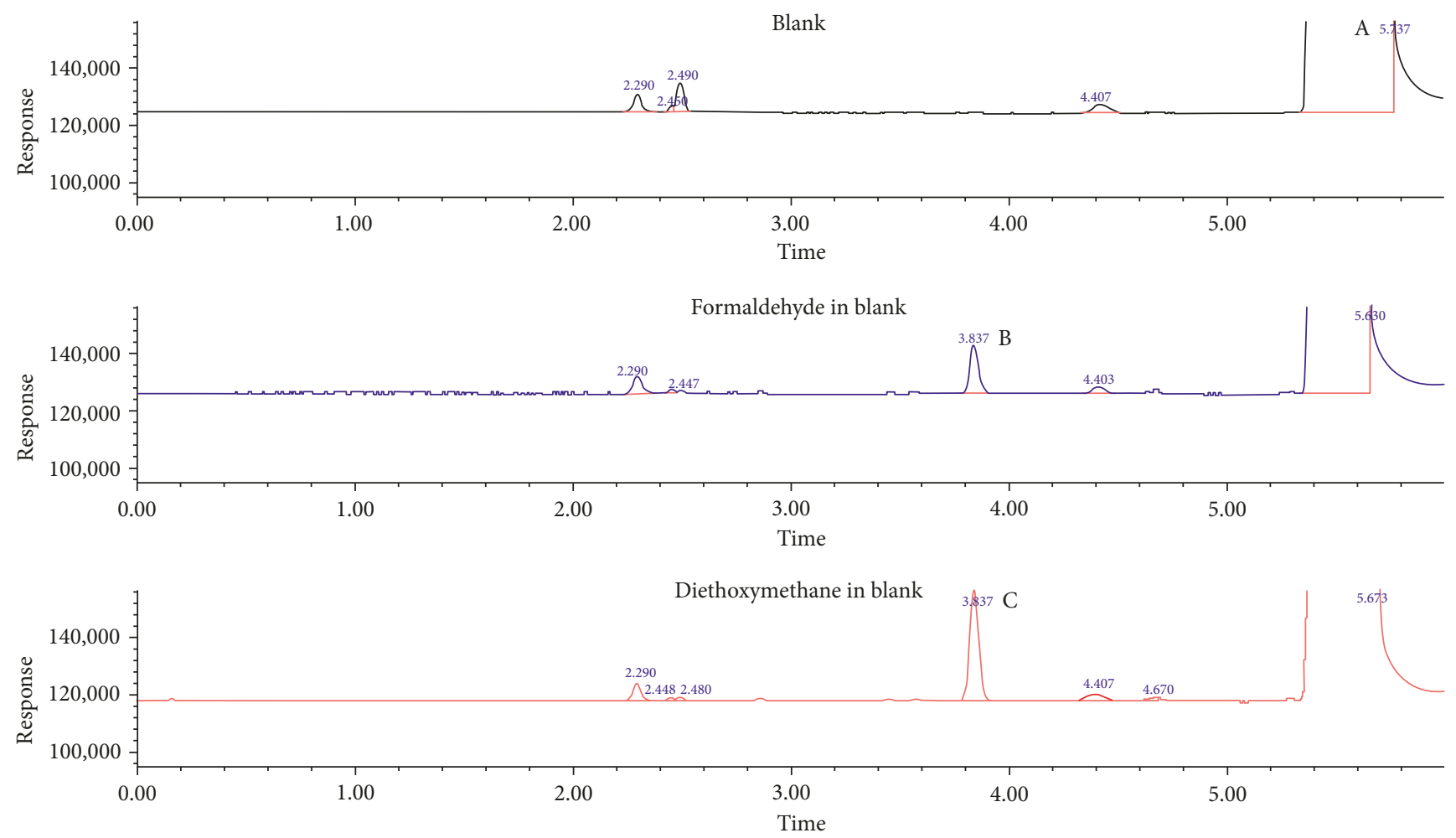

FIGURE 1: Overlaid chromatograms show the conversion of formaldehyde in acidified ethanol to the corresponding derivative. (A) Ethanol; (B) formaldehyde derivative; (C) diethoxymethane standard.

2.8. Statistical Analysis. Results were statistically processed by $t$-test or one-way analysis of variance (ANOVA) in order to evaluate significant differences $(p<0.05)$. Statistical Package for the Social Sciences (SPSS, 20) software was used for this purpose.

\section{Results and Discussion}

\subsection{Development and Optimization of SHS-GC-FID Method}

\subsubsection{Chromatographic Conditions}

(1) Identification. The identification of the derivative, the product of the chemical reaction of formaldehyde with ethanol, was confirmed by using the corresponding standard (diethoxymethane). As shown in Figure 1(B), the retention time of formaldehyde derivative peak $\left(t_{R}=3.837 \mathrm{~min}\right)$ matched with that belonging to the corresponding standard peak eluted according to Figure $1(\mathrm{C})$. This indicates that the derivative was diethoxymethane.

To further confirm the identity of formaldehyde derivative, EI mass spectrum of the corresponding peak (shown in Figure 2) in full scan was acquired and identified using the NIST MS library as diethoxymethane.

\subsubsection{Optimization of Sample Preparation and Headspace Sampling}

(1) Preliminary Investigation. At the beginning, the sample preparation and the headspace sampling parameters described by del Barrio et al. [16] (the sample concentration: $100 \mathrm{mg} / \mathrm{mL}$; the headspace parameter: incubation at $60^{\circ} \mathrm{C}$ for $15 \mathrm{~min}$ ) were applied for analyzing and evaluating the recovery of formaldehyde derivative from the spiked samples of PEG 400 and PVP K-30. The results $(n=2)$ demonstrated that the mean recovery of formaldehyde derivative from PEG 400 was within the acceptable range (80-120\%); however, it was not so for PVP K-30 (56\%).

In order to explore the factors that leaded to such low recovery of formaldehyde derivative from PVP K-30, the sample matrix effect and the previous incubation parameters were checked. First, the experiments carried out on the ethanolic solution of diethoxymethane standard showed that the incubation time of $15 \mathrm{~min}$ at the temperature of $60^{\circ} \mathrm{C}$ was sufficient for diethoxymethane to reach the static headspace equilibrium. Second, the mean recovery of diethoxymethane standard was $110 \%(n=2)$ when preparing PVP K-30 samples by adding $5 \mathrm{~mL}$ of the ethanolic standard solution. Thus, there is no negative effect of PVP K-30 sample matrix on formaldehyde derivative extraction. Third, the incubation time required to complete the derivatization reaction of formaldehyde in PVP K-30 was evaluated at the temperature of $60^{\circ} \mathrm{C}$. As shown in Figure 3, the incubation for $15 \mathrm{~min}$ was not sufficient for completing the derivatization reaction of formaldehyde. Rather, the incubation time should be adjusted at $45 \mathrm{~min}$ at least to ensure completion of the reaction. This difference in the incubation times required for 


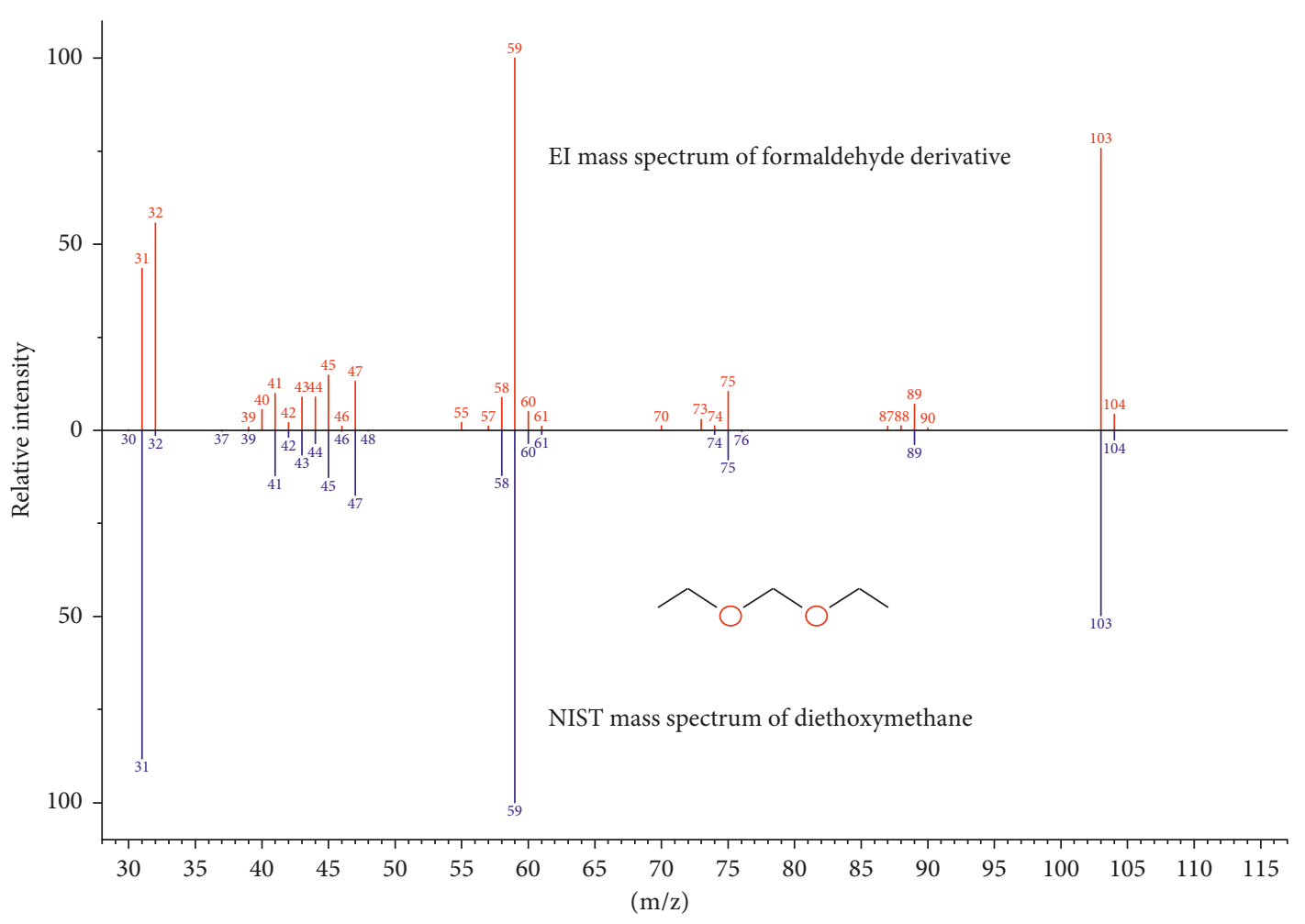

Figure 2: EI mass spectrum of formaldehyde derivative.

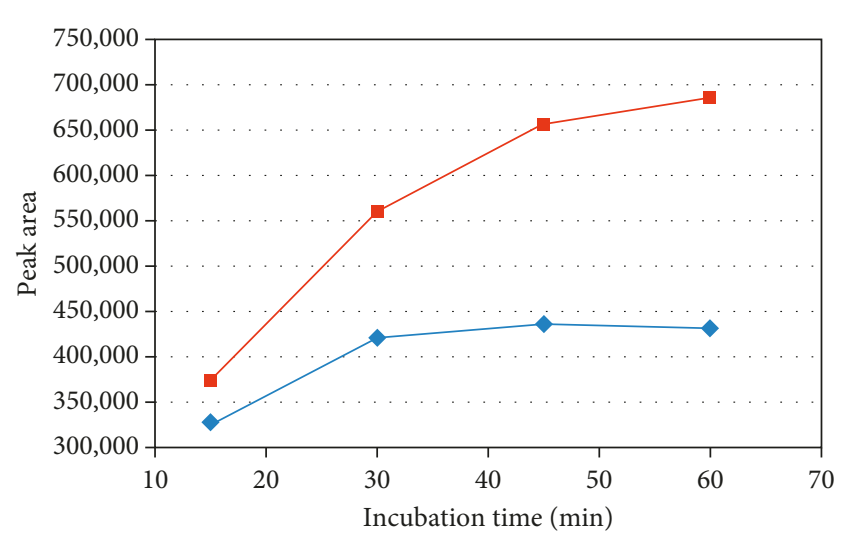

FIgURE 3: Effect of incubation time at $60^{\circ} \mathrm{C}$ on formaldehyde derivative peak area in PVP K-30 when the sample concentration is $50 \mathrm{mg} / \mathrm{mL}$ (blue box) and $100 \mathrm{mg} / \mathrm{mL}$ (red box).

PVP K-30 sample may be due to existence of a relationship between the physical nature of the sample and the kinetic of the derivatization reaction of formaldehyde.

(2) Effect of Sample Dilution on Incubation Time. The relatively high viscosity of ethanolic solution of PVP K-30, when prepared at concentration of $100 \mathrm{mg} / \mathrm{mL}$, may be the reason behind the long time required to reach equilibrium for formaldehyde derivative (Figure 3). Although sample dilution can decrease sensitivity of the analytical method, however, it can reduce viscosity of the ethanolic solution of PVP K-30, which can in turn decrease the required time for both completing the derivatization reaction and reaching equilibrium for formaldehyde derivative between the sample and the headspace gas phases [24]. Therefore, the sample concentration of $50 \mathrm{mg} / \mathrm{mL}$ was used to evaluate the required incubation time for the spiked PVP K-30 samples while fixing the incubation temperature at $60^{\circ} \mathrm{C}$. Figure 3 shows the diagram which correlates between the peak area of the derivative and the increased incubation time. The results demonstrated that there was no significant increase in the peak area of formaldehyde derivative after $30 \mathrm{~min}$ incubation.

As a consequence, sample dilution from $100 \mathrm{mg} / \mathrm{mL}$ to $50 \mathrm{mg} / \mathrm{mL}$ gave the advantage of lowering the incubation time to $30 \mathrm{~min}$ (instead of $45 \mathrm{~min}$ at least). Therefore, the sample concentration of $50 \mathrm{mg} / \mathrm{mL}$ was selected to complete the other experiments.

(3) Effect of Increasing the Incubation Temperature. Increasing the incubation temperature generally leads to an increase in the rate of the derivatization reaction and the headspace sensitivity. On the other hand, it results in decreasing the required time to reach the static headspace equilibrium [24]. Therefore, the incubation temperature was raised to $70^{\circ} \mathrm{C}$ (higher temperatures were not experimented to avoid any potential degradation of the samples). The results (shown in Table 1) indicate that there was no significant increase ( $t$-test, $p>0.05$ ) in the detector response when the reaction mixture was incubated at $70^{\circ} \mathrm{C}$ (instead of $60^{\circ} \mathrm{C}$ ) for $30 \mathrm{~min}$. Hence, there was no increase in the sensitivity. In contrast, the incubation time required to complete the derivatization reaction of formaldehyde in 
TABLE 1: Effect of incubation temperature on response $(n=2)$.

\begin{tabular}{lc}
\hline Incubation temperature $\left({ }^{\circ} \mathrm{C}\right)$ & Response $($ mean $\pm \mathrm{SD})$ \\
\hline 60 & $230299 \pm 4872$ \\
70 & $233366 \pm 4779^{\mathrm{a}}$ \\
\hline
\end{tabular}

${ }^{a}$ No significant difference when compared with incubation at $60^{\circ} \mathrm{C}$.

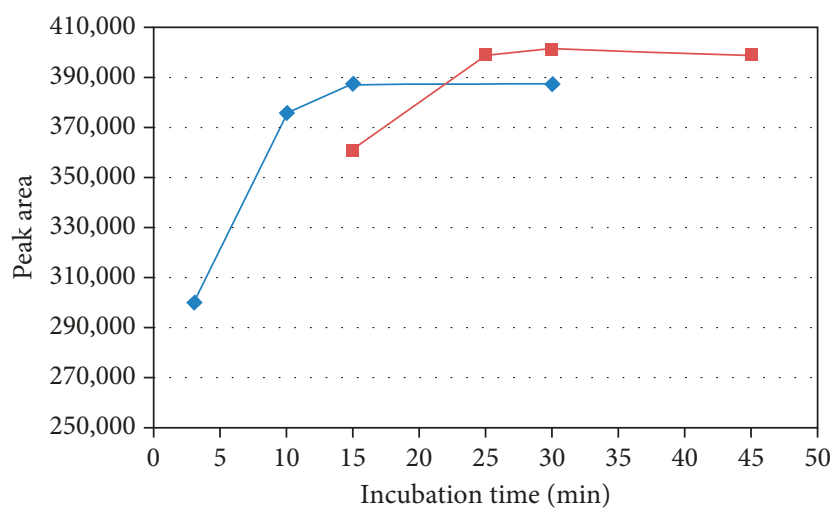

FIgURE 4: Effect of incubation time at $70^{\circ} \mathrm{C}$ on formaldehyde derivative peak area. Formaldehyde in PVP K-30 (red box) and formaldehyde in PEG 400 (blue box).

excipient samples decreased. Figure 4 shows the plateau of the peak area of formaldehyde derivative with increase in incubation time at $70^{\circ} \mathrm{C}$ for both PEG 400 and PVP K-30. The data show no significant increase in the peak area of formaldehyde derivative after $15 \mathrm{~min}$ for PEG 400 and 25 min for PVP K-30.

As a consequence, the increasing of incubation temperature from $60^{\circ} \mathrm{C}$ to $70^{\circ} \mathrm{C}$ leaded to a decrease in the incubation time from more than $15 \mathrm{~min}$ to $15 \mathrm{~min}$ for PEG 400 and from $30 \mathrm{~min}$ to $25 \mathrm{~min}$ for PVP K-30. Therefore, the incubation temperature of $70^{\circ} \mathrm{C}$ was selected.

(4) Headspace Sampling Parameters. Headspace sampling parameters other than incubation time (injection speed and injection volume) were optimized and set in a way that can achieve a balance between the sensitivity and the peak shape parameters. The final headspace sampling parameters are given in Section 2.3.

3.1.3. Effect of Water Presence on Formaldehyde Determination. Diethoxymethane formation reaction is susceptible to water presence which can reverse the reaction $[16,26]$. Therefore, the tolerance of the derivatization reaction of formaldehyde to water was evaluated by adding it to several vials containing $5 \mathrm{~mL}$ of the reaction mixture (formaldehyde in acidified ethanol at a concentration of $1.5 \mu \mathrm{g} / \mathrm{mL}$ ) at the following amounts: $0,12.5,25$, and $50 \mathrm{mg}$ $(0,5,10$, and $20 \% \mathrm{w} / \mathrm{w}$ relative to the sample weight $250 \mathrm{mg})$. After analysis and statistical processing, the results (shown in Table 2) manifested that there was no significant difference (ANOVA test, $p>0.05$ ) between the control ( $0 \%$ water) and the other samples.
As a consequence, excipient samples containing water $\leq 20 \%(\mathrm{w} / \mathrm{w})$ can be analyzed without any significant effects on formaldehyde determination. Higher amounts of water were not experimented because the acceptable limits of water content stated in the monographs of PEG and PVP are $1-2 \%$ and $5 \%$, respectively $[5,6]$.

\subsection{SHS-GC-FID Method Validation}

3.2.1. Specificity. The specificity of the method was determined by comparing the chromatograms (Supplementary Material Figure S1) of the blank (acidified ethanol), the stressed excipients dissolved in ethanol and the standard solution of formaldehyde in the blank. The chromatograms showed that there were no interferences at the retention time of formaldehyde derivative peak. In addition, all volatile component peaks, which appeared after analyzing spiked excipient samples, dissolved in the blank (Supplementary Materials Figures S2 and S3) were completely separated from the analyte peak (the resolution between the analyte peak and any other one was more than 2).

3.2.2. Linearity. The linearity of the method was evaluated from injection of nine concentrations of formaldehyde at the range of $0.25-50 \mu \mathrm{g} / \mathrm{ml}$. The analyte showed excellent linear behavior over the specified range with coefficient of correlation $\left(R^{2}\right)$ value of 1 .

3.2.3. Accuracy. The accuracy of the optimized method was determined by spiking the excipient samples with known amounts of formaldehyde at four concentration levels $(n=3)$. The results (shown in Table 1) were expressed as mean recoveries. The recovery at all concentration levels was within the acceptable range (80-120\%). This indicates that the method is accurate.

3.2.4. Precision. The precision of the method was evaluated in terms of the repeatability (expressed as intraday precision) and the intermediate precision (expressed as interday precision). The repeatability of the method was established from triplicate $(n=3)$ injections of each spiked excipient sample at each concentration level. Intermediate precision (interday precision) was carried out by analyzing the spiked excipient samples, prepared in the same way and at the same concentration levels, on two different days by two different analysts. The results of the method precision (shown in Table 3) were expressed as a relative standard deviation (RSD\%). All RSDs were less than $4 \%$. This indicates that the method is precise.

3.2.5. Limits of Detection and Quantification. The limits of detection and quantification (LOD and LOQ, resp.) were evaluated based on signal-to-noise ratios of 3 and 10, respectively, and the respective values were found to be 121.80 and $406.00 \mu \mathrm{g} / \mathrm{L}$. Because the sample concentration was $50 \mathrm{mg} / \mathrm{mL}$, LOD in excipient samples was $2.44 \mu \mathrm{g} / \mathrm{g}$, while LOQ was $8.12 \mu \mathrm{g} / \mathrm{g}$. 
TABLE 2: Effect of water content on formaldehyde determination $(n=2)$.

\begin{tabular}{|c|c|c|c|c|}
\hline Percentage of water relative to sample weight (\%) & 0 & 5 & 10 & 20 \\
\hline Formaldehyde concentration $(\mu \mathrm{g} / \mathrm{mL})($ mean $\pm \mathrm{SD})$ & $1.45 \pm 0.025$ & $1.48 \pm 0.009^{\mathrm{a}}$ & $1.48 \pm 0.025^{\mathrm{a}}$ & $1.48 \pm 0.015^{\mathrm{a}}$ \\
\hline
\end{tabular}

${ }^{a}$ No significant difference when compared with the control ( $0 \%$ water).

TABle 3: Accuracy, intraday, and interday precision of the developed method.

\begin{tabular}{lcccccc}
\hline $\begin{array}{l}\text { Formaldehyde } \\
\text { spiked }(\mu \mathrm{g} / \mathrm{g})\end{array}$ & $\begin{array}{c}\text { Mean recovery K-30 } \\
\%(n=3)\end{array}$ & $\begin{array}{c}\text { Intraday precision } \\
(\mathrm{RSD} \%)(n=3)\end{array}$ & $\begin{array}{c}\text { Interday precision } \\
(\mathrm{RSD} \%)(n=6)\end{array}$ & $\begin{array}{c}\text { Mean recovery } \\
\%(n=3)\end{array}$ & $\begin{array}{c}\text { Intraday precision } \\
(\mathrm{RSD} \%)(n=3)\end{array}$ & $\begin{array}{c}\text { Interday precision } \\
(\mathrm{RSD} \%)(n=6)\end{array}$ \\
\hline 10.0 & 104.27 & 2.65 & 1.92 & 87.76 & 0.75 & 3.18 \\
50.04 & 98.14 & 1.48 & 1.56 & 89.79 & 1.59 & 3.24 \\
500.4 & 98.99 & 2.96 & 3.61 & 97.70 & 2.04 & 2.67 \\
1000.9 & 97.89 & 1.52 & 1.56 & 101.12 & 2.07 & 2.05 \\
\hline
\end{tabular}

TABLE 4: Comparison between the methods used to determine formaldehyde in excipients or drug substances.

\begin{tabular}{|c|c|c|c|c|c|c|}
\hline $\begin{array}{l}\text { Analytical } \\
\text { technique }\end{array}$ & $\begin{array}{l}\text { Derivatization and/or } \\
\text { extraction times }(\mathrm{min})\end{array}$ & $\begin{array}{l}\text { Run time } \\
(\min )\end{array}$ & $\begin{array}{c}\text { Approx. recovery } \\
(\%)\end{array}$ & $\begin{array}{c}\text { Approx. precision }^{\mathrm{a}} \\
(\%)\end{array}$ & $\begin{array}{l}\text { Approx. } \mathrm{LOD}^{\mathrm{b}} \\
(\mathrm{ppm})\end{array}$ & Ref. \\
\hline GC-FID & 5 & $>7$ & No data & No data & 7 & {$[21]$} \\
\hline GC-MS & 240 & 15 & $86-99$ & 3.7 & 0.02 & [19] \\
\hline SHS-GC-FID & 30 & 5 & $85-97$ & $\leq 3$ & 0.05 & {$[20]$} \\
\hline SHS-GC-MS & 20 & 28 & No data & 3.1 & 0.05 & {$[20]$} \\
\hline SPME-HS-GC-MS & 60 & 22.5 & $106.5-113.5$ & $3.13-13.19$ & No data & {$[18]$} \\
\hline HPLC-UV & No data & $\geq 35$ & $84-97$ & $0.5-1.2$ & 0.5 & {$[22]$} \\
\hline HPLC-UV & 60 & 30 & No data & No data & 0.03 & {$[15]$} \\
\hline HPLC-UV & No data & No data & 94.9-102.9 & No data & 10 & {$[23]$} \\
\hline Proposed method & 15 or 25 & 11 & $87.8-104.3$ & $0.75-3.6$ & 2.44 & - \\
\hline
\end{tabular}

${ }^{a}$ Including inter- and intraday precision; ${ }^{b}$ LOD in sample; ${ }^{c}$ SPME: solid-phase microextraction.

3.2.6. Robustness. Changing the flow rate within $\pm 0.1 \mathrm{~mL} / \mathrm{min}$ had no effect on the area of formaldehyde derivative peak, and all RSDs were less than 5\%. This indicates the robustness of the method.

3.3. Performance of the Proposed Method. Little analytical methods have been developed to determine formaldehyde in pharmaceutical excipients [13]. Table 4 shows a comparison between these methods and the proposed one.

Compared to other methods, the time required to complete formaldehyde determination using the developed method was generally faster. Recovery obtained with the presented procedure was comparable with those reported by others. Precision of the method was also close to those mentioned by others; however, it was better than that for SPME-based method. Although the proposed method had lower sensitivity than most of the other methods, however, it gives the opportunity to detect and determine formaldehyde impurity in pharmaceutical excipients below the limit stated in British pharmacopoeia (15 ppm for free formaldehyde in PEG) [5].

3.4. Analysis of Commercial Pharmaceutical Excipient Samples. PVP and PEG are widely used in many
TABLE 5: Formaldehyde level in the excipient samples.

\begin{tabular}{lcc}
\hline Company & Excipient & Formaldehyde level $(\mu \mathrm{g} / \mathrm{g})$ \\
\hline A & PVP K-30 & ND $^{\mathrm{a}}$ \\
B & PVP K-30 & $\mathrm{ND}^{\mathrm{a}}$ \\
C & PVP K-30 & $3.51^{\mathrm{b}}$ \\
D & PVP K-25 & 8.04 \\
E & PEG 400 & 22.47 \\
F & PEG 400 & $3.64^{\mathrm{b}}$ \\
G & PEG 300 & 190.58 \\
\hline
\end{tabular}

${ }^{\mathrm{a}}$ Not detected; ${ }^{\mathrm{b}}$ formaldehyde level $<$ QL.

pharmaceutical applications and dosage forms. They are utilized in drug products over a wide range of concentrations. These concentrations can reach up to $67 \%$ for PEG 400 and $25 \%$ for various grades of PVP $[3,27]$.

The optimized SHS-GC-FID method was applied to analyze the presence of formaldehyde in several commercial PEG and PVP samples. The results of the analysis are summarized in Table 5.

Formaldehyde content in the excipient samples was extensively varied from 8.04 to $190.58 \mu \mathrm{g} / \mathrm{g}$. These variations depended on the nature, the storage conditions, and the source of the excipient samples. 
Formaldehyde was not detected in PVP K-30 samples from the companies A and B. However, PVP samples (from the companies $\mathrm{C}$ and $\mathrm{D}$ ) contained trace amount of formaldehyde. Actually, there is no specific pharmacopoeial limit for formaldehyde in PVP, but there is a general limit for aldehydes (500 ppm) which expressed as acetaldehyde [5, 6].

According to British Pharmacopoeia, the limit of formaldehyde in PEG is 15 ppm [5]. Both PEG 400 from the company E and PEG 300 from the company $G$ had formaldehyde levels exceeding the identified limit.

Although PVP K-25 from the companies C and D and PEG 400 from the company $F$ contained trace levels of formaldehyde, however, such levels may cause critical drug products instability and degradation, especially when excipient/active pharmaceutical ingredient ratio is high, according to many literatures $[1,2,4]$.

\section{Conclusion}

A SHS-GC-FID method was developed and validated for determination of formaldehyde in pharmaceutical excipients. Samples were simply prepared in headspace vials by adding acidified ethanol as a diluent and derivatization reagent. After that, the vials were automatically moved to the incubator where formaldehyde derivative was simultaneously formed and extracted. The developed method was linear, specific, accurate, and precise over the specified range. The limits of detection and quantification were 2.44 and $8.12 \mu \mathrm{g} / \mathrm{g}$, respectively. The method was also simple and rapid, and it does not require sophisticated instrumentations or large amounts of solvents. This method was used to screen PEG and PVP samples for formaldehyde. The tested samples contained varying levels of it. So, the method could be valuable in selecting appropriate excipients and/or excipient batches for pharmaceutical formulation. It is also important for selecting approved vendors of pharmaceutical excipients. In addition, it can be applied as a tool for testing the quality of pharmaceutical excipients routinely.

\section{Conflicts of Interest}

The authors declare that they have no conflicts of interest.

\section{Acknowledgments}

The authors greatfully acknowledge the Assistant Prof. Dr. Manal Daghestani, Dr. Faten Alsaka, Dr. Ghassan Abochameh, and Ph.D. student Yamen Alsalka for helping in carrying out analysis and data processing.

\section{Supplementary Materials}

Supplementary 1. Figure S1: representative GC-FID chromatograms of specificity study.

Supplementary 2. Figure S2: GC-FID chromatogram of PEG 400 sample spiked with formaldehyde. DEM: diethoxymethane.

Supplementary 3. Figure S3: GC-FID chromatogram PVP K-30 sample spiked with formaldehyde. DEM: diethoxymethane.

\section{References}

[1] A. S. Narang and S. H. Boddu, Excipient Applications in Formulation Design and Drug Delivery, Springer International Publishing, Basel, Switzerland, 2015.

[2] M. Li, Organic Chemistry of Drug Degradation, Royal Society of Chemistry, Cambridge, UK, 2012.

[3] R. P. Gullapalli and C. L. Mazzitelli, "Polyethylene glycols in oral and parenteral formulations-a critical review," International Journal of Pharmaceutics, vol. 496, no. 2, pp. 219-239, 2015.

[4] K. K. Hotha, S. Roychowdhury, and V. Subramanian, "Drugexcipient interactions: case studies and overview of drug degradation pathways," American Journal of Analytical Chemistry, vol. 7, no. 1, pp. 107-140, 2016.

[5] British Pharmacopeia, British Pharmacopeia Commission, London, UK, 2013.

[6] USP, The United States Pharmacopeia, USP 39-NF 34, United States Pharmacopeial Convention, Rockville, MD, USA, 2016.

[7] S. T. Colgan, T. C. Zelesky, R. Chen et al., "Use of activated carbon in packaging to attenuate formaldehyde-induced and formic acid-induced degradation and reduce gelatin crosslinking in solid dosage forms," Journal of Pharmaceutical Sciences, vol. 105, no. 7, pp. 2027-2031, 2016.

[8] K. C. Waterman, W. B. Arikpo, M. B. Fergione et al., "Nmethylation and $\mathrm{N}$-formylation of a secondary amine drug (varenicline) in an osmotic tablet," Journal of Pharmaceutical Sciences, vol. 97, no. 4, pp. 1499-1507, 2008.

[9] G. Wang, J. D. Fiske, S. P. Jennings, F. P. Tomasella, V. A. Palaniswamy, and K. L. Ray, "Identification and control of a degradation product in Avapro ${ }^{\mathrm{TM}}$ film-coated tablet: Low dose formulation," Pharmaceutical Development and Technology, vol. 13, no. 5, pp. 393-399, 2008.

[10] M. Douša, P. Gibala, J. Havlíček, L. Plaček, M. Tkadlecová, and J. Břicháč, "Drug-excipient compatibility testing-identification and characterization of degradation products of phenylephrine in several pharmaceutical formulations against the common cold," Journal of Pharmaceutical and Biomedical Analysis, vol. 55, no. 5, pp. 949-956, 2011.

[11] Q. Zhong, S. Stowers, N. L. Segraves et al., "Degradation of a pharmaceutical in HPLC grade methanol containing trace level formaldehyde," Pharmaceutical Development and Technology, vol. 18, no. 4, pp. 877-882, 2013.

[12] B. L. Williamson, A. J. Tomlinson, P. K. Mishra, G. J. Gleich, and S. Naylor, "Structural characterization of contaminants found in commercial preparations of melatonin: similarities to case-related compounds from L-tryptophan associated with eosinophilia-myalgia syndrome," Chemical Research in Toxicology, vol. 11, no. 3, pp. 234-240, 1998.

[13] P. K. Ragham and K. B. Chandrasekhar, "A rapid UPLC-UV method development and validation for the quantitative determination of formaldehyde using derivatization technique," International Journal of Research in Pharmaceutical Sciences, vol. 6, no. 2, pp. 46-53, 2015.

[14] W. M. Haynes, CRC Handbook of Chemistry and Physics, CRC Press, Boca Raton, FL, USA, 93rd edition, 2012.

[15] J. N. Hemenway, T. C. Carvalho, V. M. Rao et al., "Formation of reactive impurities in aqueous and neat polyethylene glycol 400 and effects of antioxidants and oxidation inducers," Journal of Pharmaceutical Sciences, vol. 101, no. 9, pp. 3305-3318, 2012.

[16] M. A. del Barrio, J. Hu, P. Zhou, and N. Cauchon, "Simultaneous determination of formic acid and formaldehyde in pharmaceutical excipients using headspace GC/MS," Journal 
of Pharmaceutical and Biomedical Analysis, vol. 41, no. 3, pp. 738-743, 2006.

[17] A. Teasdale, Genotoxic Impurities: Strategies for Identification and Control, John Wiley \& Sons, Hoboken, NJ, USA, 2011.

[18] S. Zali, F. Jalali, A. Es-haghi, and M. Shamsipur, "Determination of free formaldehyde in vaccines and biological samples using solid-phase microextraction coupled to GCMS," Journal of Separation Science, vol. 36, no. 24, pp. 3883-3888, 2013.

[19] Z. Li, B. M. Kozlowski, and E. P. Chang, "Analysis of aldehydes in excipients used in liquid/semi-solid formulations by gas chromatography-negative chemical ionization mass spectrometry," Journal of Chromatography A, vol. 1160, no. 1-2, pp. 299-305, 2007.

[20] Z. Li, L. K. Jacobus, W. P. Wuelfing, M. Golden, G. P. Martin, and R. A. Reed, "Detection and quantification of lowmolecular-weight aldehydes in pharmaceutical excipients by headspace gas chromatography," Journal of Chromatography $A$, vol. 1104, no. 1-2, pp. 1-10, 2006.

[21] G. J. Manius, L. F. Wen, and D. Palling, "Three approaches to the analysis of trace formaldehyde in bulk and dosage form pharmaceuticals," Pharmaceutical Research, vol. 10, no. 3, pp. 449-453, 1993.

[22] A. Nageswari, K. V. S. R. K. Reddy, and K. Mukkanti, "Lowlevel quantitation of formaldehyde in drug substance by HPLC-UV," Chromatographia, vol. 75, no. 5-6, pp. 275-280, 2012.

[23] S. Velankar, R. Lokhande, R. Yadav, and R. Pawar, "HPLC method development and validation for determination of formaldehyde and acetaldehyde traces in drug substance," International Journal of Chemical and Pharmaceutical Analysis, vol. 3, no. 4, 2016.

[24] B. Kolb and L. S. Ettre, Static Headspace-Gas Chromatography: Theory and Practice, John Wiley \& Sons, New York, NY, USA, 2nd edition, 2006.

[25] C. F. Poole, Gas Chromatography, Elsevier, Waltham, MA, USA, 1st edition, 2012.

[26] J. Clayden, N. Greeves, and S. Warren, Organic Chemistry, Oxford University Press, New York, NY, USA, 2nd edition, 2012.

[27] R. C. Rowe, P. J. Sheskey, and M. E. Quinn, Handbook of Pharmaceutical Excipients, Pharmaceutical Press, London, UK, 6th edition, 2009. 

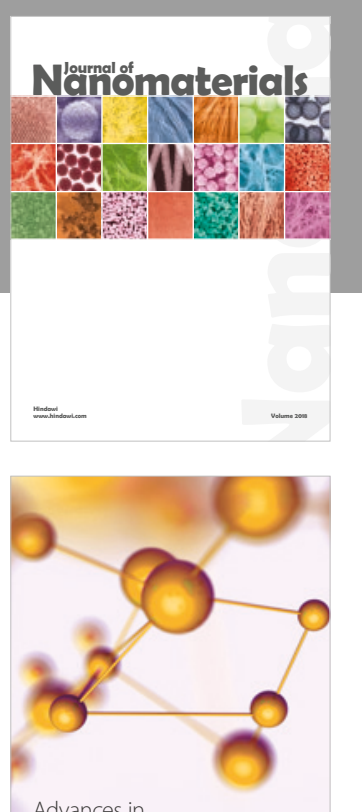

Physical Chemistry
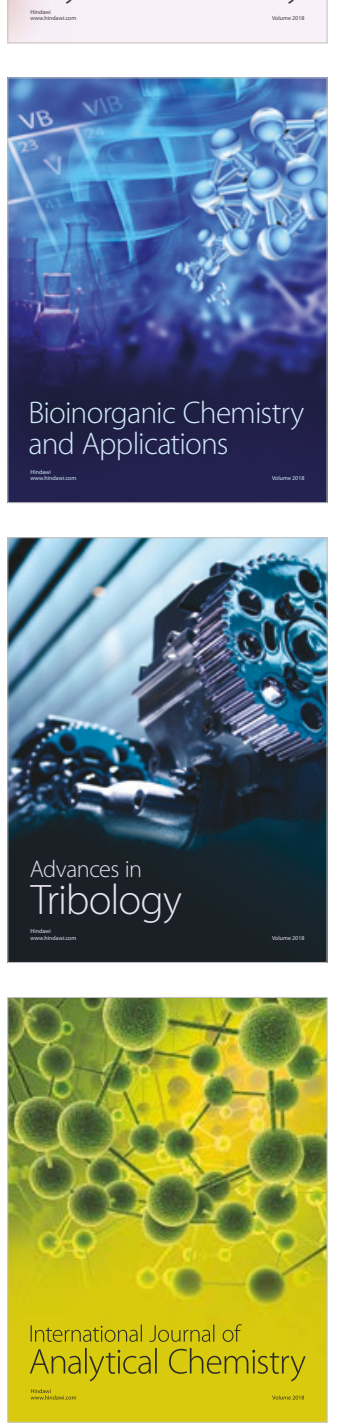

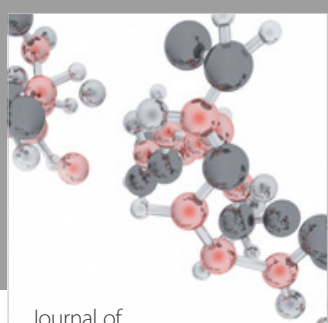

Analytical Methods

in Chemistry

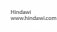

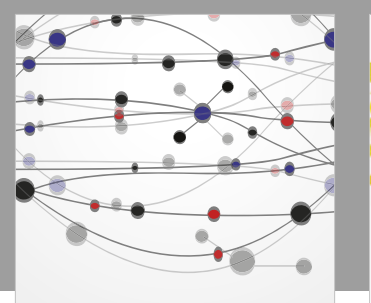

The Scientific World Journal

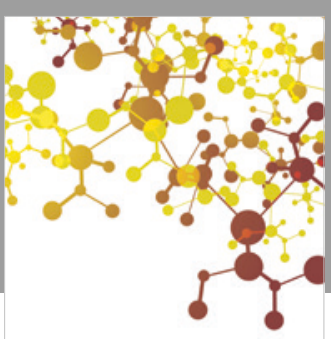

Journal of

Applied Chemistry
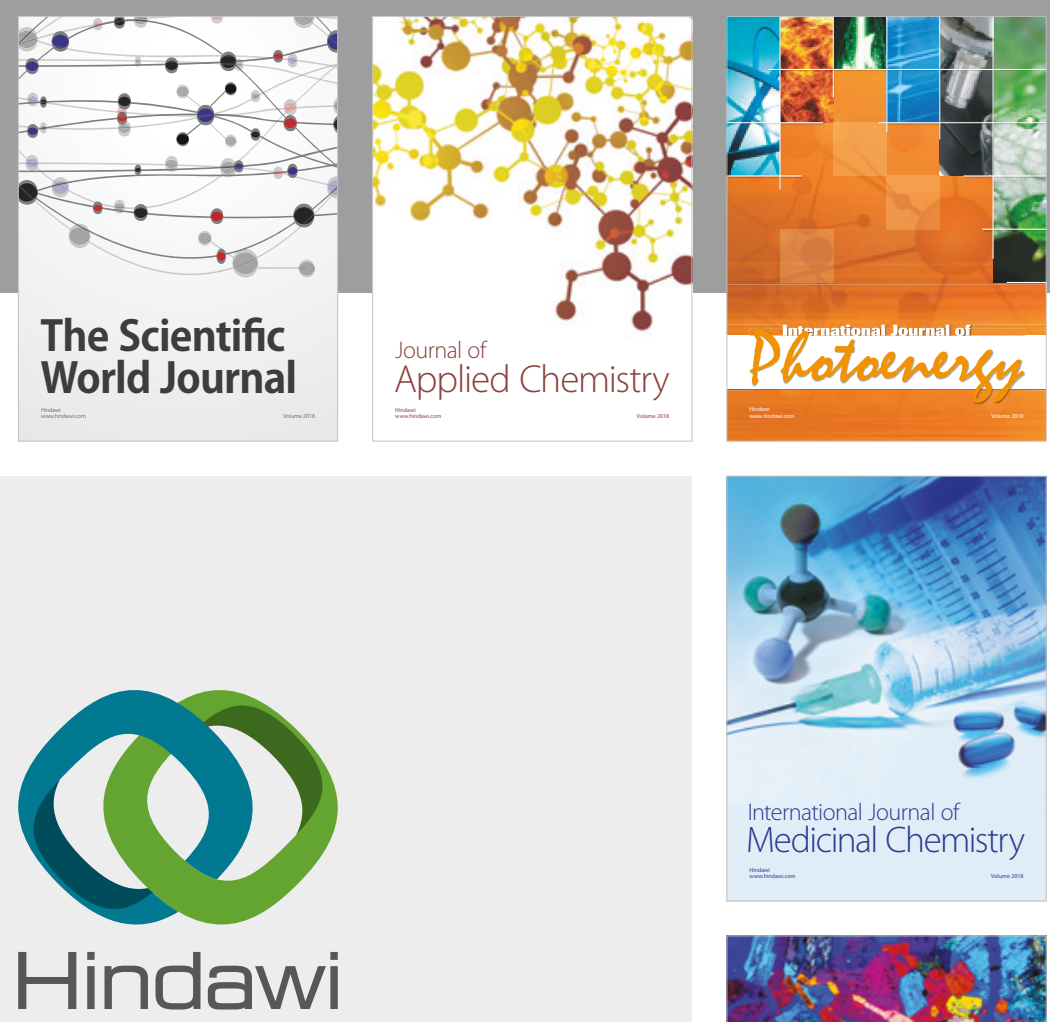

Submit your manuscripts at

www.hindawi.com
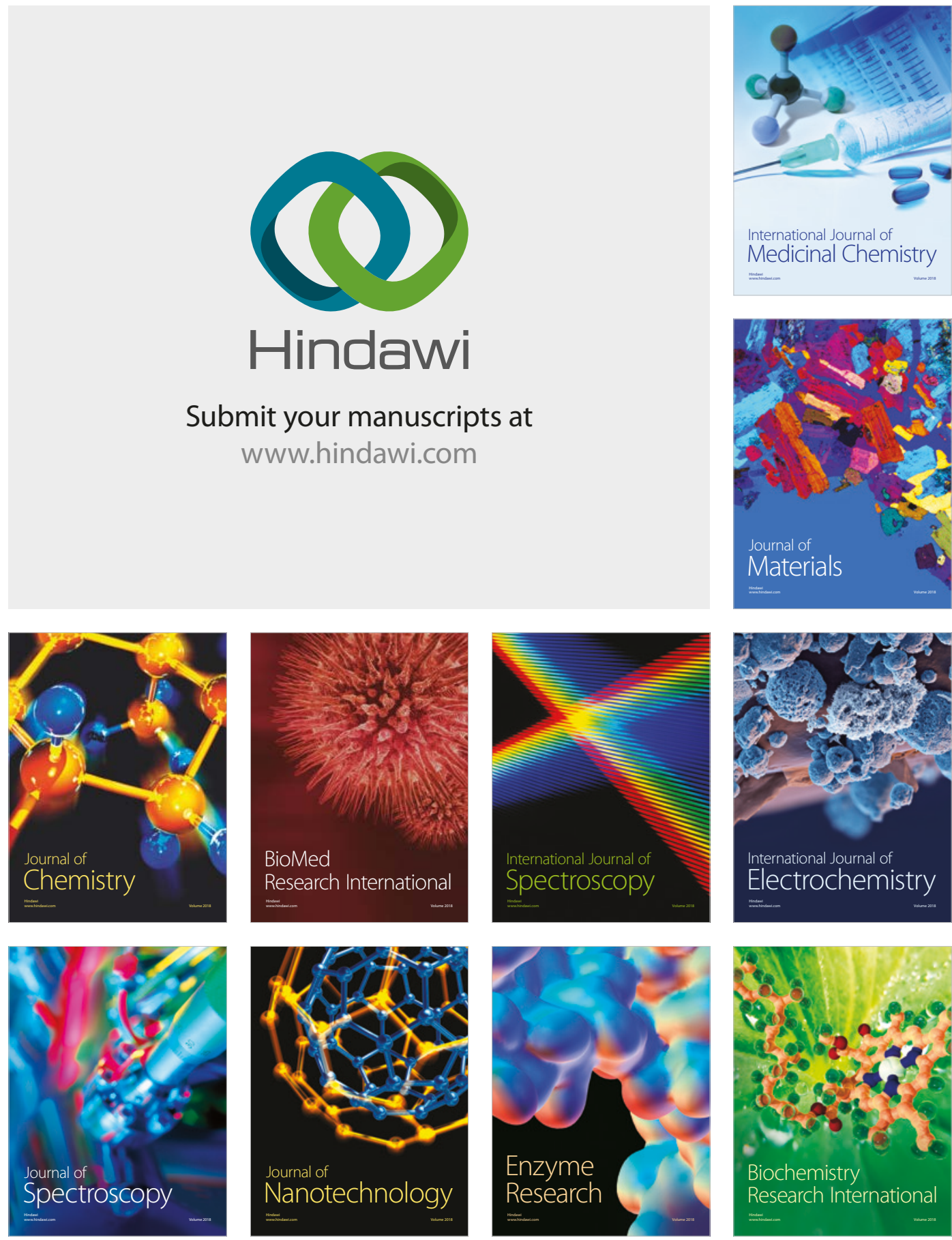
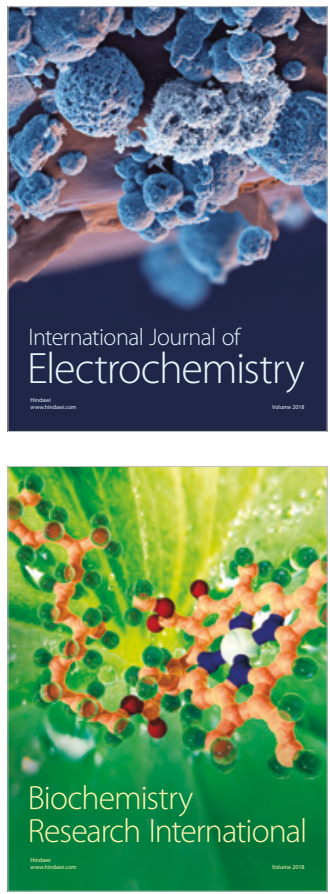